\title{
Valores Organizacionais e Concepções de Deficiência: A Percepção de Pessoas Incluídas
}

\author{
Organizational Values And Disability Conceptions: \\ The Point Of View Of Included People
}

Valores Organizacionales Y Concepciones De Deficiencia: La Percepción De Las Personas Incluidas
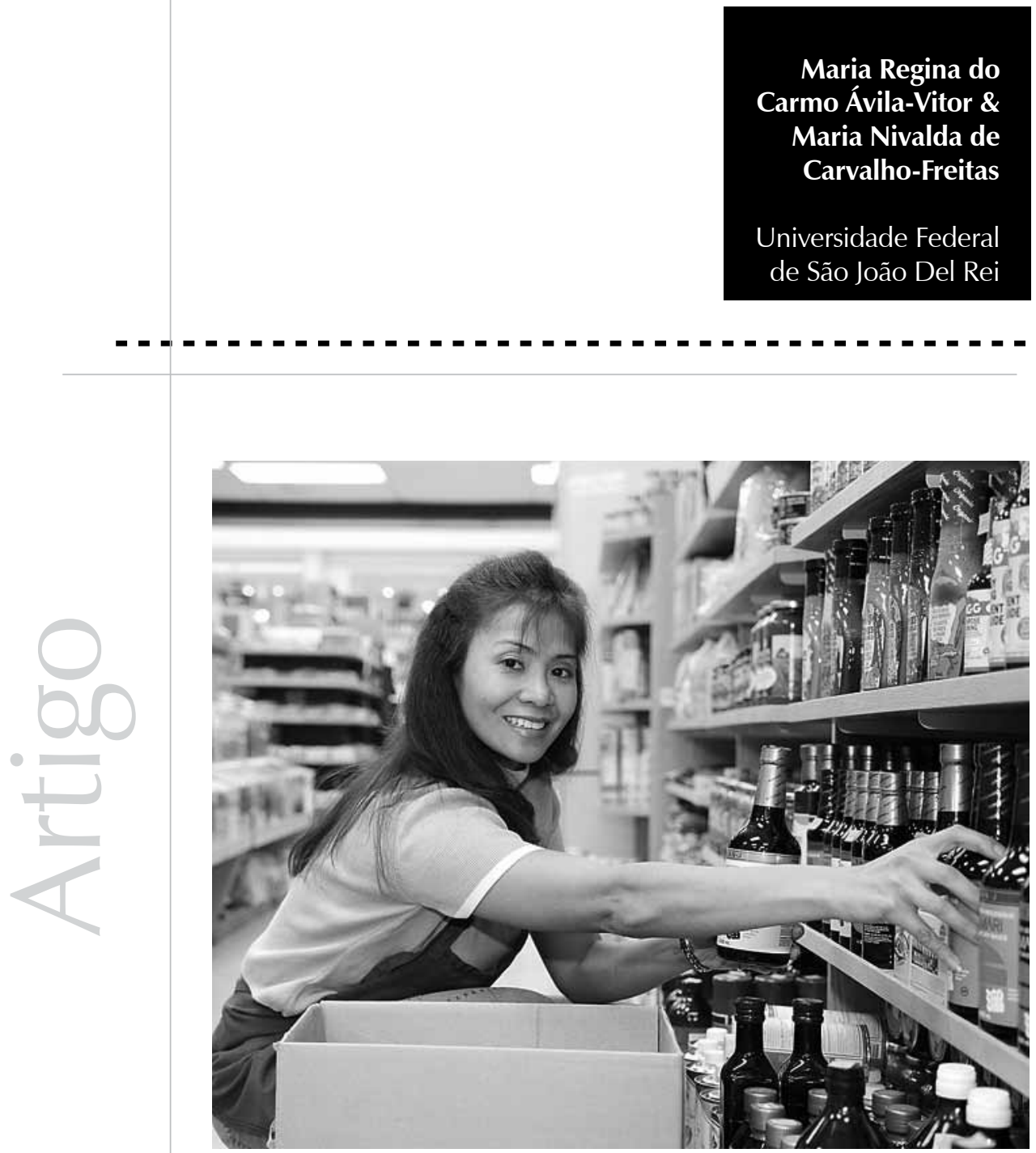
Resumo: O objetivo deste estudo foi verificar, do ponto de vista das pessoas com deficiência (PcDs) inseridas no trabalho, se havia relação entre a percepção que elas tinham dos valores organizacionais e as formas como viam a deficiência no trabalho. O estudo foi realizado em uma empresa referência em inclusão. Foram utilizados o Inventário de Concepções de Deficiência em Situações de Trabalho e o Inventário de Valores Organizacionais. Também foram feitas entrevistas com PcDs, seus gestores e coordenadores do programa de inclusão. Verificou-se que existe uma correlação negativa entre a percepção que as PcDs têm sobre o prestígio e a forma como é vista a normalidade pela empresa, isto é, as PcDs relacionam o prestígio da empresa a uma concepção de deficiência que não as coloca como um desviante de um padrão normal de ser humano. Além disso, foi possível identificar aspectos considerados importantes no processo de inserção de PcDs, como o reconhecimento da inclusão como valor organizacional, a necessidade de adequação das condições de trabalho, o papel das PcDs no processo de inclusão e a importância da convivência com PcDs em um cenário favorável ao seu desempenho.

Palavras-chave: Inclusão social. Mercado de trabalho. Deficientes. Valores.

Abstract: The aim of this article was to verify in the point of view of people with disabilities (PWDs) who are working in the labor market if there was any relation between their organizational values perceptions and the ways that they saw the disability in the workplace. The research took place in a company that is reference in inclusion in Brazil. Two questionnaires were used: the Inventory of Disability Conceptions in Work Situations and the Inventory of Organizational Values. Semi-structured interviews with PWDs, their managers and the coordinators of the inclusion program and interviews with PWDs, their managers and coordinators of the inclusion program were carried out. It was verified a negative correlation between the PWDs perception about prestige and the form as normality is seen by the company, that means that the PWDs connect the prestige of the company to a conception of deficiency that does not place them differently of a normal standard of human being. Moreover, it was possible to identify aspects considered important in the process of insertion of PWDs as the recognition of the inclusion as organizational value, the necessity of adequacy to the work conditions, the role of the PWDs in the inclusion process and the importance of the relationship with PWDs in a scene favorable to their performance.

Keywords: Social inclusion. Labor market. Disabilities. Values.

Resumen: El objetivo de este estudio fue verificar, del punto de vista de las personas con discapacidad (PcDs) inseridas en el trabajo, si había relación entre la percepción que ellas tenían de los valores organizacionales y las formas como veían la discapacidad en el trabajo. El estudio fue realizado en una empresa referencia en inclusión. Fueron utilizados el Inventario de Concepciones de Discapacidad en Situaciones de Trabajo y el Inventario de Valores Organizacionales. También se realizaron entrevistas con PcDs, sus gestores y coordinadores del programa de inclusión. Se verificó que existe una correlación negativa entre la percepción que las PcDs tienen sobre el prestigio y la forma como es vista la normalidad por la empresa, o sea, las PcDs relacionan el prestigio de la empresa a una concepción de discapacidad que no las coloca como un desviante de un estándar normal de ser humano. Además, fue posible identificar aspectos considerados importantes en el proceso de inserción de PcDs, como el reconocimiento de la inclusión como valor organizacional, la necesidad de adecuación de las condiciones de trabajo, el papel de las PcDs en el proceso de inclusión y la importancia de la convivencia con PcDs en un escenario favorable a su desempeño.

Palabras clave: Inclusión social. Mercado de trabajo. Discapacitados. Valores.

O objetivo geral deste estudo foi verificar, do ponto de vista das pessoas com deficiência (PcDs) inseridas no mercado de trabalho, se havia relação entre a percepção que elas tinham dos valores organizacionais e as formas como viam a deficiência em situações de trabalho. Para concretizar esse objetivo, definiu-se como estratégia metodológica realizá-lo em uma empresa que fosse reconhecida nacionalmente pela

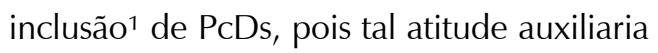
na identificação de aspectos valorizados por elas, contribuindo, assim, para se construírem referências de ações bem-sucedidas para as organizações que estão inserindo PcDs em função da Lei de Cotas.

A empresa escolhida foi a Serasa Experian, em São Paulo, devido ao seu destaque como empresa cidadã com o Programa de Empregabilidade de PcDs. Esse programa recruta e seleciona PcDs com o objetivo de desenvolver suas competências profissionais, capacitando-as para o mercado de trabalho. 
O programa faz parte da área de diversidade dentro do Desenvolvimento Sustentável da Serasa. É uma experiência considerada modelo de qualificação profissional e contratação de PcDs para diversas empresas no Brasil.

A regulamentação do trabalho das PcDs ocorreu há 20 anos, com o advento da Lei no 8.213, de 24 de julho de 1991, denominada Lei de Cotas. Essa lei assume um importante papel, pois garante a adequação ambiental e a igualdade de oportunidades no acesso ao trabalho e o cumprimento de pisos percentuais diferenciados de contratação de PcDs, dependendo do tamanho da empresa. A partir dessa implementação, começou a haver uma oferta crescente de vagas para PcDs nas empresas. Contudo, conforme Tanaka e Manzini (2005), apesar de a lei ter impulsionado a abertura de vagas nas empresas, o número de PcDs presentes no mercado de trabalho e o cumprimento dos dispositivos legais ainda estão longe de alcançar aquilo que a legislação prevê. No que se refere às PcDs, é necessário sublinhar que, antes de terem seus direitos assegurados, elas passaram por um longo histórico de exclusão na sociedade (Amaral, 1996; Alencar, 1993; Enumo, 1998; Glat, 1995; Goyo, Manzini, Carvalho, Balthazar, \& Miranda, 1989; Mendes, 1995; Mendes, Ferreira, \& Nunes, 2003; Omote, 1987; Pessotti, 1984).

No Brasil, existem 45,6 milhões de pessoas com algum tipo de deficiência de acordo com o censo realizado pelo Instituto Brasileiro de Geografia e Estatística (IBGE, 2010). Segundo os dados da Relação Anual de Informações Sociais (RAIS), o Brasil tinha, em 2010, 44.068.355 vínculos empregatícios formais e o número de PcDs no mercado de trabalho era de 306.013 , o que correspondia a $0,70 \%$ do total de vínculos (Ministério do Trabalho e Emprego - MTE, 2010). Esses resultados são compatíveis com estudos que têm indicado que as PcDs enfrentam muitas dificuldades para ingressarem e para se manterem e crescerem no mercado de trabalho (Ribeiro \& Carneiro, 2009).

O que tem acontecido é que as empresas têm se deparado com a inserção ${ }^{2}$ dessas pessoas, muitas vezes, sem preparação para tal fato (Silva, 1993; Batista, 2004; Araújo, 2007). Para Ribas (2008), somente quando se acredita que as PcDs gerem riquezas por meio de seu trabalho é que faz sentido tê-las nas empresas. As empresas inclusivas, de acordo com Sassaki (1999), são aquelas que se preparam para receber as PcDs mediante adequações ambientais e nos instrumentos de trabalho, programas de treinamentos e desenvolvimento de recursos humanos e modificações na filosofia e nos valores da organização.

O que podemos depreender desse cenário é que vivemos um momento de transição marcado por opostos em termos de inclusão de PcDs no trabalho. Há empresas, como as citadas por Ribeiro e Carneiro, que preferem as multas à contratação de PcDs e que são totalmente fechadas à inclusão, e há, por outro lado, empresas inclusivas, que se esforçam em, além de atender os dispositivos legais, criar formas efetivas de inclusão. Há ainda aquelas que começam a se abrir para a inclusão, seja porque estão pressionadas pelas leis, seja pelo fato de constatarem o bom desempenho das pessoas que possuem deficiência. A verdade é que, apesar de ainda haver um longo caminho a percorrer na luta pela inclusão de PcDs no mercado de trabalho, ocorreram nas últimas décadas profundas transformações nesse cenário, e torna-se necessário estudar o resultado dessas transformações em empresas brasileiras que se abriram a essa nova realidade. É justamente esse o objetivo deste trabalho: verificar as relações entre as concepções de deficiência e os valores organizacionais, na perspectiva das PcDs, em uma empresa considerada referência em inclusão. 


\section{Carvalho-Freitas e \\ Marques (2007), \\ ao identificarem que existiam \\ formas diferentes de qualificar e de definir a deficiência, realizaram uma análise histórica e identificaram diferentes formas de percebê-la, que possuíam características constantes, embora o contexto histórico e social se modificasse.}

${ }^{3} \mathrm{~A}$ acessibilidade se refere à garantia de acesso irrestrito aos diversos espaços e situações sociais, e envolve a eliminação das barreiras físicas, de comunicação e atitudinais.
As concepções de deficiência, na presente pesquisa, são entendidas como formas de qualificação da deficiência, atribuindo-se a ela características específicas, que se desdobram em ações que tanto podem favorecer quanto interditar a inserção social e o trabalho das PcDs (Carvalho-Freitas \& Marques, 2010). Em artigo sobre as investigações de Sadao Omote (Piccolo, Moscardini, \& Costa, 2010), é acentuada a importância de se contemplar, segundo Omote (1990, 1997), os critérios adotados para se definir a deficiência, pois serão as interpretações conferidas pelos outros (audiência) à deficiência que se materializarão em ações políticas, médicas, psicológicas ou educacionais. Omote (1999) enfatiza a importância da concepção de deficiência como construção social que desloca a atenção do indivíduo para o meio e, sem ignorar as dimensões biológicas da deficiência, coloca ênfase nas repercussões dos significados atribuídos à deficiência pela sociedade. Nessa direção, também CardosoBuckley (2011) reflete sobre as implicações das visões da pessoa para a pesquisa em educação especial. Por outro lado, Moraes, Lima e Mansolo (2011) focalizam a concepção dominante de deficiência e questionam a lógica instituída da deficiência como desvio ou anormalidade, chamando a atenção para a necessidade de problematizar essa visão e de buscar brechas para a assunção da diferença como possibilidade de potência e de criação.

Carvalho-Freitas e Marques (2007), ao identificarem que existiam formas diferentes de qualificar e de definir a deficiência, realizaram uma análise histórica e identificaram diferentes formas de percebêla, que possuíam características constantes, embora o contexto histórico e social se modificasse. A essa tipologia, denominaram matrizes de interpretação da deficiência ou concepções de deficiência, que se traduz em uma atribuição de características diferenciadas à deficiência, com repercussões políticas, ideológicas, psicológicas e sociais para as PcDs. As matrizes operacionalizadas por Carvalho-Freitas e Marques (2010) e que têm sido utilizadas em pesquisa são: a espiritual, a baseada em princípios da normalidade, a matriz da inclusão e os fatores relacionados ao desempenho, ao vínculo das PcDs com o trabalho e aos benefícios da contratação dessas pessoas (Nascimento, Damasceno, \& Assis, 2011; Carvalho-Freitas \& Marques, 2009; Lara, Ávila, \& CarvalhoFreitas, 2008; Carvalho-Freitas, 2009; Nepomuceno \& Carvalho-Freitas, 2008; Brite, 2009; Carvalho-Freitas \& Marques, 2010; Carvalho-Freitas \& Gomes, 2010).

Tendo por referência o fato de que a Lei de Cotas estimula a inserção de PcDs nas organizações de trabalho, além de identificar a forma como a deficiência é vista, faz-se necessário identificar se os valores da organização podem contribuir para entender como as próprias PcDs veem suas possibilidades de trabalho. Schur, Kruse e Blanck (2005) afirmam que poucos estudos têm abordado a relação entre fatores sociais dentro das organizações e as experiências de emprego das PcDs. Nesse contexto, esses pesquisadores indicam a importância de avaliar a cultura corporativa e a percepção das PcDs, indo além das pesquisas de atitudes e das opiniões dos empregadores.

Schein, $(1992,1999)$ descreve três níveis de cultura dentro das organizações. O mais fundamental consiste nos valores e nas normas que orientam uma organização, manifestandose na forma de crenças, nem sempre conscientes e explícitas, que guiam as ações das pessoas. O segundo nível são os valores assumidos explicitamente na organização, por meio de suas estratégias e objetivos, refletidos em suas políticas organizacionais, e o terceiro são as manifestações ou artefatos da cultura, que incluem o espaço fisico e o ambiente social em uma empresa. Os diferentes níveis de cultura, muitas vezes, se reforçam mutuamente; contudo, incongruências e conflitos podem existir entre eles. 
Segundo Tamayo e Gondim (1996), os valores organizacionais são princípios ou crenças que orientam a vida da empresa. Para Dias (2005), o sistema de valores de uma organização é vivenciado como uma experiência subjetiva compartilhada, e possibilita a simbolização e a mediação das necessidades individuais e organizacionais. Conforme Deal e Kennedy (1988), os valores definem o direcionamento de uma organização e influenciam seu comportamento, constituindo-se em um componente fundamental da identidade organizacional. Para Tamayo (2008), os valores organizacionais possuem algumas características distintivas: podem ser considerados formas de conhecer a realidade organizacional, isto é, o que a organização avalia como bom e desejável para si mesma; "funcionam como necessidades que determinam o comportamento orientado a um fim" (2008, p. 311), são elementos estruturantes da organização e são compartilhados por seus membros.

\section{Metodologia}

\section{Participantes}

Na primeira etapa da pesquisa, participaram 15 PcDs, conforme pode ser visto na Tabela 1.

Tabela 1. Caracterização da amostra pesquisada ( $n=15$ PcDs)

\begin{tabular}{llll}
\hline Variável & Observações & Variável & Observações \\
\hline Sexo & Masculino $=8(53,3 \%)$ & Tipo de & Física $=9(60,0 \%)$ \\
& Feminino $=7(46,7 \%)$ & Deficiência & Auditiva $=3(20,0 \%)$ \\
& & & Visual $=3(20,0 \%)$
\end{tabular}

$\begin{array}{ll}\text { Ano de } & 2000=1 \\ \text { admissão } & 2003=1 \\ \text { na } & 2004=2 \\ \text { empresa } & 2005=4 \\ 2006 & =1 \\ 2007 & =2 \\ 2008 & =1 \\ 2009 & =3\end{array}$

Respondente Sede/SP $=7$

por agência Joinville/SC $=1$

da João Pessoa/PB = 1

Serasa

São José dos Campos/SP = 1

Juiz de Fora/MG $=1$

Teresina/PI = 1

Antônio Carlos/SP $=1$

Cuiabá/MT $=1$

Passo Fundo/RS $=1$

Escolaridade Ens. médio incompleto $=1$ Cargos

Auxiliar administrativo $=10$

Ens. médio completo $=4 \quad$ ocupados

Assistente $=1$

Superior incompleto $=3$

Auxiliar de escritório $=1$

Superior completo $=6$

Operador de circuito fechado

Especialização $=1$

de televisão (CFTV) $=1$

Atendimento $=1$

Advogado júnior $=1$ 
Das 15 pessoas que responderam aos questionários, a distribuição entre os sexos é praticamente igual, oito, ou seja, $53,3 \%$ são do sexo masculino e sete, $46,7 \%$, do sexo feminino. Com relação ao tipo de deficiência que possuem, nove $(60 \%)$ pessoas possuem deficiência física, três (20\%), deficiência auditiva e três (20\%), deficiência visual. Com relação ao grau de escolaridade, pode-se perceber que nenhuma pessoa tem formação de nível fundamental; todas têm escolaridade entre o ensino médio e a especialização. As PcDs vêm sendo contratadas pela empresa desde 2000, tendo como referência a amostra pesquisada. Com relação à locação das PcDs que responderam a esta pesquisa, sete trabalham na sede da Serasa em São Paulo e os outros oito estão alocados em outras agências da organização. Em relação ao cargo dos respondentes, a maioria ocupa o cargo de Auxiliar Administrativo, embora um advogado faça parte da amostra.

A amostra da segunda etapa da pesquisa contou com dez participantes, divididos em três grupos: o primeiro é o grupo dos dois coordenadores do Programa de Empregabilidade de PcDs, que também possuem deficiência; o segundo é o grupo de quatro gestores de PcDs, que responderam a entrevistas semiestruturadas sobre a inclusão de PcDs na empresa, e o terceiro é o grupo de quatro PcDs, que responderam a entrevistas semiestruturadas. As PcDs que participaram dessa segunda etapa da pesquisa e que responderam às entrevistas foram selecionadas pela organização, e cada uma apresentava um tipo de deficiência (física, auditiva, visual e síndrome de Down).

\section{Instrumentos}

Foram utilizados três instrumentos de coleta de dados: um questionário sociodemográfico, contendo questões sobre escolaridade, tipo de deficiência, tempo de empresa etc., o
Inventário de Concepções de Deficiência em Situações de Trabalho (ICD-ST) (CarvalhoFreitas \& Marques, 2010) e o Inventário de Valores Organizacionais (IVO) (Oliveira \& Tamayo, 2004, adaptado por Dias, 2005).

O ICD-ST é também um questionário cujos itens se encontram associados a uma escala Likert de seis possibilidades de resposta, sendo elas: (1) discordo totalmente, (2) discordo muito, (3) discordo pouco, (4) concordo pouco, (5) concordo muito e (6) concordo totalmente. O respondente deve assinalar a opção que mais se assemelha ao seu grau de concordância com os 19 itens que compõem o questionário. O ICD-ST utilizado possui seis fatores: 1. a matriz da deficiência como fenômeno espiritual, que associa a deficiência a uma origem espiritual e tem como consequência a predominância de comportamentos pautados na caridade e na compaixão, na forma de lidar com as PcDs, 2. a normalidade como matriz de interpretação: as pessoas que compartilham dessa concepção têm na normalidade sua referência predominante de avaliação das pessoas, e associam a deficiência a problemas orgânicos ou intelectuais. A inserção será consequência da possibilidade de adequação da PCD aos espaços sociais, 3. a inclusão como matriz de interpretação: é pautada no modelo social da deficiência e é compartilhada pelas pessoas que acreditam na garantia de igualdade de direito de pertencimento social para todos e que associam a deficiência a uma dificuldade da sociedade em ser capaz de oferecer condições de exercício da cidadania para todas as pessoas. Nessa perspectiva, a inserção das PcDs será decorrente das possibilidades de adaptação da sociedade e das organizações de trabalho para ser acessível a todos, 4. o desempenho como fator de análise: seu foco é na funcionalidade e na capacidade produtiva das pessoas. $\mathrm{O}$ pressuposto subjacente é de que as PcDs têm pior desempenho, produzem com pior qualidade, têm maiores problemas de 
relacionamento e são mais suscetíveis aos acidentes de trabalho, 5. o fator vínculo das PcDs com o trabalho: seu foco é colocado no comprometimento e na estabilidade do trabalho das PcDs. Credita-se a essas pessoas maior comprometimento e estabilidade que às demais pessoas, 6 . os benefícios da contratação de PcDs como fator de análise: a avaliação das pessoas recai nos possíveis benefícios advindos da contratação de PcDs para a imagem da organização e para o clima organizacional.

O IVO é um questionário cujos itens se encontram associados a uma escala de concordância do tipo Likert, constituída de sete possibilidades de resposta, sendo elas: (1) nada parecida, (2) muito pouco parecida, (3) pouco parecida, (4) moderadamente parecida, (5) parecida, (6) muito parecida e (7) extremamente parecida. Nesse inventário, o respondente deve analisar o quanto a organização em que trabalha se parece com a organização descrita nos 25 itens desse instrumento de pesquisa. O IVO conta com seis fatores: 1. autonomia: neste fator, os itens se referem à busca do aperfeiçoamento constante do empregado e da organização, que se expressa por meio de competência, curiosidade, criatividade, variedade de experiência, definição de objetivos profissionais de seus empregados e abertura para os desafios, 2. bem-estar do empregado: este fator indica a preocupação por parte da empresa em proporcionar satisfação ao empregado, atentando para a qualidade de vida no trabalho, 3. conformidade: neste fator, os itens fazem referência à definição de limites das ações organizacionais e comportamentos de seus membros, priorizando o respeito a regras e modelos de comportamentos tanto no ambiente de trabalho quanto no relacionamento com outras organizações, 4. prestígio social: os itens que compõem este fator se relacionam ao poder. A organização busca prestígio, admiração e respeito da sociedade por causa da qualidade dos seus produtos ou serviços, 5. domínio e ética organizacional: este fator contém itens que se referem ao poder, e tem como meta principal a obtenção de status e a busca de uma posição dominante no mercado, além de estarem presentes itens que se relacionam aos valores que orientam o relacionamento cotidiano com indivíduos próximos e com a comunidade, 6. realização: este fator é composto por itens que representam valores que têm o sucesso como meta central e que demonstram competência tanto da organização como dos seus empregados.

Procedimentos de coleta e análise de dados A pesquisa foi realizada em duas etapas: uma quantitativa, que envolveu a utilização de questionários, e a outra qualitativa, com a realização de entrevistas. A coleta de dados para a primeira etapa da pesquisa foi feita por meio da internet, no site de pesquisa chamado EncuestaFacil. O link para os questionários foi enviado por e-mail para todas as 85 PcDs que trabalham na Serasa e para seus gestores. Obtiveram-se respostas de 15 PcDs e de um gestor. Na categoria de PcDs, esse número representa $17 \%$ de resposta. Esse índice, segundo Malhotra (2001), é um índice esperado pela literatura na área para surveys por e-mail (em torno de 15\%). Como, na categoria de gestores, tivemos somente um respondente, essa categoria foi excluída da análise. Sendo assim, a amostra da primeira etapa da pesquisa foi uma amostra de conveniência, composta por 15 PcDs que trabalham na Serasa e que se dispuseram a responder à pesquisa. Foi feita a análise estatística descritiva de cada inventário e depois a correlação de Spearman entre os dados dos dois inventários, a fim de verificar se existia relação entre esses dois construtos. A segunda etapa foi realizada na sede da organização estudada, e foi utilizada a metodologia de entrevistas semiestruturadas com os coordenadores do Programa de Empregabilidade, com quatro PcDs e com 
seus gestores. Nessa segunda etapa da pesquisa, a abordagem qualitativa, foi utilizada a metodologia de análise de conteúdo. As questões das entrevistas se relacionavam à forma como percebiam a deficiência, aos valores da organização e ao Programa de Empregabilidade de PcDs da empresa. As entrevistas foram feitas individualmente, mediante a autorização dos participantes, e foram gravadas e transcritas na íntegra, além de ter sido feita a categorização das unidades que se repetiram. Também foi feita uma análise documental, visando à caracterização das políticas de inserção de PcDs praticadas pela empresa.

\section{Caracterização da empresa onde foi realizado o estudo}

A Serasa foi fundada em 1968, em uma ação cooperada entre os bancos que buscavam informações rápidas e seguras para dar suporte às decisões de crédito. Hoje a Serasa facilita cerca de quatro milhões de negócios por dia. A partir de 2007, a Experian, líder mundial no fornecimento de serviços de informação, marketing e gerenciamento de crédito a organizações e consumidores, adquiriu o controle acionário da empresa.

A Serasa Experian possui como visão "ser a primeira em cada uma das maiores economias da América Latina e liderar a inovação e a transformação do mercado de soluções de informação como primeira escolha dos nossos clientes" e, como missão, "desenvolver e integrar conhecimento, tecnologia e serviços de informação para apoiar a validação de dados, decisões de crédito e de marketing direto, gerando valor para nossos profissionais, clientes, acionistas, fornecedores e sociedade, promovendo o desenvolvimento sustentável" (Serasa Experian, 2011).

Em 2001, a Serasa criou o Programa Serasa de Empregabilidade de Pessoas com Deficiência. Esse programa recruta e seleciona PcDs com o objetivo de desenvolver suas competências profissionais, capacitando-as para o mercado de trabalho. Segundo o coordenador do programa, em entrevista para esta pesquisa, a Serasa nunca teve suas portas fechadas à inclusão de PcDs. Porém, o programa estruturado de inclusão teve início em 2001, e, em 2008, ampliou o seu trabalho, fazendo parceria com outras empresas que investem financeiramente no programa e que têm como retorno a contratação de PcDs, que saem do Programa de Empregabilidade com formação para realizar o trabalho.

O Programa de Empregabilidade de Pessoas com Deficiência faz parte da área de diversidade dentro do Desenvolvimento Sustentável da Serasa. É uma experiênciamodelo de qualificação profissional e de contratação de PcDs para diversas empresas no Brasil. A cada semestre, 50 PcDs são formadas no Programa de Empregabilidade de Pessoas com Deficiência da Serasa. Em 2003, a empresa criou o Fórum Serasa Experian de Empregabilidade de Pessoas com Deficiência, que acontece a cada três meses e que tem por objetivo trocar experiências e contribuir para o crescimento da empregabilidade de PcDs no País.

As pessoas que têm interesse em participar do programa devem ser PcDs física, visual ou auditiva, serem maiores de 16 anos, estarem cursando ou terem concluído o ensino médio ou o ensino superior, com exceção das PcDs intelectuais, que podem não ter concluído o ensino médio; além disso, devem possuir facilidade de aprendizagem, independência, autonomia e autoestima. Essas pessoas cadastram seu currículo no site da organização e é feita uma pré-seleção para participar do programa.

Ao longo de quatro meses, as pessoas selecionadas cumprem uma carga horária de 412 horas, com disciplinas divididas em três módulos. O primeiro módulo é voltado para 
o aprimoramento da identidade profissional; o segundo, para o conhecimento técnico, e o terceiro, com foco na orientação profissional, busca alocar as pessoas contratadas na área de maior interesse e aptidão do contratado. $\mathrm{O}$ treinamento é diário, com duração de quatro horas por dia.

É importante ressaltar que todas as PcDs que são contratadas pela Serasa, em seu processo de adaptação à empresa, contam com os tutores, que são alguns funcionários da empresa responsáveis por ajudá-las nesse processo inicial até que estejam adaptadas. A adaptação não possui um tempo determinado. Geralmente, acontece em no máximo dois meses, porém depende da PCD. Quando estão adaptadas ao local de trabalho, as PcDs perdem seus tutores. Para as pessoas com síndrome de Down, os tutores são permanentes. Além disso, a Serasa conta com a parceria da Associação para o Desenvolvimento Integral do Down (ADID), que faz um acompanhamento mais pessoal e individualizado. A ADID é uma instituição que oferece apoio pedagógico para a inserção de pessoas com síndrome de Down no mercado de trabalho.

Com relação à acessibilidade 3 arquitetônica, a Serasa buscou atender à maior gama de variações antropométricas possível da população em sua sede em São Paulo. O prédio da empresa é considerado um edifícioconceito, e já foi reconhecido com duas premiações. A primeira foi o Prêmio AsBEA 2003, concedido pela Associação Brasileira dos Escritórios de Arquitetura, e a segunda foi o 13을 Prêmio Master Imobiliário 2007, reconhecido como um novo paradigma de sustentabilidade e de acessibilidade em edifícios corporativos.

O prédio também ganhou certificados importantes, como a Certificação NBR 9050:94 de Acessibilidade a Edificações, Espaço, Mobiliário e Equipamentos Urbanos.
Foi o pioneiro no Brasil nessa certificação, e, em 2006, foi também o primeiro a renovar a certificação e a mantê-la em 2007. Um dado importante, salientado por Lucca (2008), é que a participação dos Ser Serasa (denominação dada aos funcionários da empresa) que possuem deficiência no projeto do prédio permitiu a sugestão de melhorias para a NBR original, que foram aceitas pela Associação Brasileira de Normas Técnicas (ABNT, 2004).

\section{Resultados}

Serão apresentados, a seguir, os resultados das duas etapas da pesquisa. Da primeira etapa, serão apresentados os valores organizacionais e as concepções de deficiência compartilhados pelas PcDs da empresa estudada. Na segunda etapa, serão apresentados os aspectos considerados relevantes na inclusão de PcDs no trabalho a partir da análise das entrevistas realizadas.

\section{Análise descritiva do IVO}

As médias encontradas para os itens do IVO oscilaram dentro do intervalo 4,47 e 6,40, e os desvios-padrão variaram no intervalo de 0,640 a 1,922. Grande parte das respostas está no polo de maior valor, variando de 4 a 7 , o que demonstra que a empresa, na percepção das PcDs, tem grandes semelhanças com a organização idealizada pelo IVO em todos os fatores contemplados pelo construto.

No fator autonomia, as médias encontradas nesta pesquisa foram altas $(5,67$ a 6,13$)$, mostrando que as PcDs acreditam que a organização valorize a independência de ideias e o direito do indivíduo de procurar sua direção e promoção, além da sua independência de buscar experiência afetiva positiva. 
No fator bem-estar do empregado, as médias encontradas nesta pesquisa variaram entre 4,47 e 6,33, com desvio-padrão entre 0,724 e 1,922. Os altos valores encontrados nas médias de cada item deste fator revelam que as PcDs acreditam que a empresa se preocupe com a sua qualidade de vida, realize projetos sociais que contribuam para o bem-estar e proponha atividades que deem prazer ao empregado, pois, para ela, é importante que o empregado se sinta satisfeito.

O fator conformidade obteve uma média de 5,88, o que situa a Serasa, na percepção das PcDs, como muito parecida com a empresa idealizada no IVO. O conteúdo dos itens deste fator faz referência à definição de limites das ações da empresa e aos comportamentos de seus membros, priorizando o respeito às regras e aos modelos de comportamentos no ambiente de trabalho e no relacionamento com outras organizações.

No fator prestígio, encontrou-se a média de 6,15 . A alta média encontrada neste fator pode relacionar-se com a própria visão da organização, que é: "Ser a primeira em cada uma das maiores economias da América Latina e liderar a inovação e a transformação do mercado de soluções de informação, como primeira escolha dos nossos clientes" (Serasa Experian, 2011). A visão da organização demonstra que ela deseja liderar o mercado de seu negócio e conquistar a admiração de todos os clientes, fazendo com que a Serasa seja a sua primeira escolha por meio da qualidade dos produtos e serviços que oferece. Esse valor da organização é refletido na percepção que as PcDs têm sobre ela.

No fator domínio e ética, a média encontrada foi de 6,25, e o desvio-padrão variou de 0,704 a 1,280 . A alta média encontrada neste fator revela que as PcDs concordam com a concepção de que a Serasa acredita no valor da honestidade, quer ser bemsucedida, honra seus compromissos com pessoas e organizações, considera ser fiel a seus empregados e clientes, considera importante ser competitiva, considera a segurança nos negócios muito importante e sente-se satisfeita com os seus rendimentos quando eles superam as despesas. Nos relatórios da empresa, é sempre salientada a importância do comportamento ético dos funcionários da empresa. Com relação às regras de comportamento, elas são expressas na organização por intermédio do Código de Conduta Ética Serasa Experian - Ser Ético. Esse código é um guia para que a empresa possa transmitir, a partir de suas atitudes e comportamentos, a linha de pensamento e a atuação da empresa.

No fator realização, a média encontrada foi de 6,16, e o desvio-padrão variou de 0,743 a 1,082. A alta média encontrada neste fator revela que, segundo as PcDs, a Serasa valoriza a competência, pois julga ser importante o empregado demonstrar suas habilidades e conhecimentos e conhecer bem o trabalho que realiza.

Verifica-se que, para as PcDs que participaram da pesquisa, os valores da organização em que trabalham são reconhecidos como presentes no cotidiano de trabalho. Nesse sentido, a empresa deixa claro para as pessoas o que considera desejável: os comportamentos mais autônomos, circunscritos dentro das regras estabelecidas pela organização (conformidade), os valores éticos, a busca de competitividade no mercado, o bem-estar dos empregados e o prestígio da organização.

\section{Análise Descritiva do ICD-ST}

No fator espiritual, encontrou-se a média de 2,82, o que demonstra que os respondentes discordam pouco dos pressupostos da matriz espiritual. No fator normalidade, encontrouse a média de 2,63, o que demonstra que 
os respondentes discordam pouco dos pressupostos da matriz normalidade. $\mathrm{Na}$ matriz inclusão, um alto resultado encontrado neste fator, que foi o caso deste estudo $(5,567)$, indica grande concordância de que, se a organização modifica suas condições de trabalho, as PcDs podem desempenhar adequadamente suas atividades.

A matriz desempenho tem o foco na percepção das pessoas sobre o desempenho, a produtividade e a qualidade do trabalho das PcDs. Um alto valor nessa matriz indica uma percepção negativa em relação ao desempenho e à qualidade de trabalho de uma PCD. Pelos valores encontrados nesses itens (média: 1,566), pode-se concluir que as PcDs possuem uma percepção positiva em relação ao desempenho e à qualidade de trabalho que realizam.

No fator vínculo, o foco está na percepção das pessoas sobre o comprometimento e a estabilidade das PcDs no trabalho. $\mathrm{O}$ alto valor neste fator indica que as pessoas têm uma percepção mais positiva do comprometimento e da estabilidade das PcDs no trabalho do que a das pessoas que não têm deficiência. A média encontrada neste fator foi de 3,933, o que indica que os respondentes concordam pouco com os pressupostos dessa matriz, isto é, que o vínculo das PcDs é diferente do das demais pessoas.

No fator benefício, o foco está na percepção do impacto da contratação das PcDs para a imagem e o clima da organização. $\mathrm{O}$ alto valor no resultado deste fator indica que as pessoas têm uma percepção positiva desse impacto. A média encontrada neste fator foi de 5,022, o que indica que os respondentes concordam muito com os pressupostos desta matriz e têm uma percepção positiva do impacto da contratação das PcDs para a imagem e o clima da organização.
Em relação às concepções de deficiência, foi possível identificar que as PcDs da empresa compartilham os pressupostos de que, asseguradas condições de trabalho adequadas, elas são capazes de realizar seus trabalhos e de ter um bom desempenho, e que a sua contratação tem impacto positivo na imagem e no clima da organização.

\section{Correlações entre os construtos de ICD-ST, IVO e dados sociodemográficos}

Não foram encontradas correlações significativas entre os fatores dos inventários e os dados sociodemográficos. Entre os fatores dos dois inventários utilizados, ICD-ST e IVO, apenas uma correlação foi identificada: a correlação entre o fator do IVO denominado prestígio e o fator do ICD-ST denominado normalidade, indicando que, quanto maior é a concordância com o fator prestígio, menor é a concordância com os pressupostos da normalidade (Spearman $=-0,523, p<$ $0,05)$. Sendo assim, os aspectos de prestígio da Serasa entre outras organizações, na sociedade e entre clientes, para as PcDs que trabalham na organização, associam-se ao fato de a Serasa não contratar PcDs somente para alguns setores e também ao fato de a Serasa não acreditar que as PcDs possuam atitudes inadequadas e sejam mais propensas a acidentes, de discordar que as instituições especializadas sejam mais adequadas às PcDs do que as organizações e de acreditar que as PcDs não tenham mais problemas de relacionamento que as demais pessoas. Sendo assim, pode-se dizer que as PcDs têm uma percepção positiva do prestígio da empresa que se relaciona a uma forma de ver, por parte da Serasa, a PCD, que não a coloca como um desviante de um padrão normal, e, sim, que acredita que ela tenha capacidades e que trabalhe para potencializá-las. 
Resultado -

\section{Segunda Etapa Da Pesquisa}

\section{Análise das entrevistas}

A análise das entrevistas possibilitou a identificação de algumas categorias consideradas aspectos relevantes no processo de inclusão de PcDs no trabalho, que serão apresentadas a seguir.

Inclusão como valor organizacional (primeiro aspecto): para os respondentes, o fundamental para quem trabalha com PcDs nas organizações é fazer com que este tema seja enraizado na cultura da empresa, expressando-se como um valor a ser compartilhado. Para isso, no entanto, é necessário provar que as PcDs têm bom desempenho e dão resultado. Quando a inclusão é um tema superficial e não é enraizado na cultura organizacional, ela pode ser considerada somente uma estratégia de marketing, uma vitrine da empresa.

Eu tenho pra mim que está havendo um processo de amadurecimento das empresas, não de todas, principalmente das grandes e notadamente daquelas que têm uma área de responsabilidade social, cidadania empresarial, sustentabilidade, seja lá o nome que se dê pra aqueles que estão lá dentro olhando não apenas pro sapato que está sendo fabricado ou produto financeiro, mas olhando pra fora. Este olhar pra fora é algo que todas as empresas têm que ter, e isto é importante, porém, (...) outras empresas já não são tão assim, por mais que a gente tente levar esse espírito pra eles, chegam lá as pessoas com deficiência, passa um mês, passam dois meses e a empresa não faz nenhuma adequação necessária para o desenvolvimento do trabalho dessa pessoa (coordenador do Programa de Empregabilidade).

Em relação à necessidade de adequação das condições de trabalho (segundo aspecto), as PcDs entrevistadas enfatizaram a importância das adequações feitas pela empresa como um elemento que assegura a possibilidade de um bom desempenho profissional. Para duas dessas pessoas, por exemplo, “o imprescindível é o leitor de tela. As outras adaptações, como impressoras em braile, placas de sinalização que ajudam na localização auxiliam também, mas o imprescindível para uma pessoa cega é o software leitor de tela, oferecido pela empresa".

A importância do papel desempenhado pelas PCDs no processo de inclusão (terceiro aspecto) é compartilhado pelas PcDs e pelos gestores. Segundo eles, as PcDs podem tanto abrir como fechar as portas para quem vem depois delas. De acordo com o coordenador do programa, que também é uma PCD:

Eu acho falsa a ideia de que a empresa tem que abrir as suas portas para as PCDs. Ela tem que trazer pra dentro, sem que nós tenhamos muito claro o papel que a gente está cumprindo na empresa. É muito importante saber que existe uma fronteira que tem que ser enxergada, embora ela não seja muito nítida, que divide o direito do privilégio. Então, a partir do momento que você não é uma $P C D$, mas se eu quiser te contratar aqui na Serasa, eu vou esperar de você uma resposta, uma performance, um cumprimento de metas, um comprometimento. Então, é isso que nós esperamos deles. Não adianta o gestor ser bonzinho, o gestor ser tolerante, o gestor ser... se a pessoa não corresponde. Então, é importante ter a ideia do caminho de duas mãos. O que eu estou querendo dizer é que nós, se quisermos ser, de fato, profissionais, nós temos que ter identidade profissional.

É interessante notar que é na tensão entre as PcDs e a organização que as responsabilidades de cada uma se configuram para assegurar a inclusão: a empresa, que precisa tornar a inclusão um valor e garantir as condições de adequação das condições e práticas de trabalho, e as PcDs, que precisam se preparar para assegurar o desempenho e os resultados esperados.

Esses aspectos, considerados relevantes na inclusão, refletem as estratégias adotadas no Programa de Empregabilidade da empresa, cujo foco é a capacitação das PcDs, sendo 
oferecidas, a elas, a formação e as adequações das condições e dos instrumentos de trabalho e cobrados os resultados. A premissa de oferecer as condições necessárias é assegurada para não colocar as PcDs em posição de desvantagem em relação às outras pessoas.

Na convivência com as PCDs em condições adequadas de inclusão como facilitadora do processo (quatro aspecto), foi possível identificar algumas questões relevantes, como a percepção tanto das PcDs quanto dos gestores de que a convivência é uma grande aliada na minimização dos preconceitos em relação à deficiência, sendo ressaltado pelos gestores que esse é o melhor treinamento para lidar com eles. Além disso, a análise qualitativa das entrevistas possibilitou verificar que, mesmo sendo uma empresa referência em inclusão, é possível identificar diversas dificuldades de adaptação e de socialização das PcDs: foram relatadas, por exemplo, dificuldades no acompanhamento inicial de PcDs pelos gestores, quando não tinham clareza das necessidades da PCD, dificuldades das PcDs na adaptação inicial ao trabalho e dificuldades consideradas comuns no processo de socialização, que independem do fato de se ter ou não deficiência. É importante sublinhar que as pesquisas têm indicado que apenas a convivência entre pessoas com e sem deficiência não é um fator que facilita o processo de inclusão, e pode, inclusive, contribuir para o recrudescimento dos preconceitos (Monteiro, 2006; Shannon, Tansey, \& Schoen, 2009). O resultado da presente pesquisa se insere em um contexto em que a concepção de deficiência baseada nos pressupostos da inclusão (foco nas adaptações das condições de trabalho para ser acessível a todos) é predominante, sendo, nesse cenário, a convivência um fator que contribui para fortalecer a crença nas possibilidades de trabalho das PcDs (CarvalhoFreitas \& Marques, 2009; Shannon, Tansey, \& Schoen, 2009).

\section{Discussão}

Considerando os resultados encontrados referentes ao construto de valores organizacionais, verifica-se que a Serasa se parece muito com a empresa idealizada pelo construto. Tendo como referência os pressupostos de Katz e Kahn (1978) de que os valores atuam como elementos integradores entre as normas (expectativas da organização) e a prescrição dos papéis (formas de comportamento), a percepção das PcDs de que os valores da Serasa são muito próximos dos valores ideais ratifica o discurso oficial de responsabilidade social da empresa; além disso, confirma a importância do comprometimento da alta gestão da organização para as políticas de inclusão de PcDs, discutida por Schur et al. (2005) .

Em relação às concepções de deficiência, verificase que a predominância de concordância foi em relação à matriz inclusão, o que indica que os respondentes possuem uma percepção positiva em relação às possibilidades de trabalho das PcDs, considerando a importância de oferecer condições de igualdade a todos mediante a adequação das condições de trabalho e da acessibilidade. Baixos valores de média foram encontrados na matriz desempenho, o que indica que os respondentes desta pesquisa avaliam positivamente o desempenho, a produtividade e a qualidade do trabalho das PcDs. Os resultados encontrados no fator vínculo indicam que os respondentes veem as PcDs como comprometidas e estáveis no trabalho. A alta média encontrada no fator benefício revela que os respondentes concordam muito com os pressupostos da matriz benefício, o que indica que possuem uma percepção positiva do impacto da contratação das PcDs para a imagem e o clima da organização.

Considerando que os respondentes da pesquisa são PcDs, verifica-se que têm uma percepção positiva das suas próprias possibilidades de trabalho, considerando, principalmente, que acreditam que, sendo feitas as adequações das condições de trabalho, terão bom desempenho e que a sua contratação beneficia a imagem e o clima da organização. Nesse sentido, veem a própria contratação como uma vantagem competitiva para a organização, ratificando achados de pesquisas anteriores realizadas com grupos de gestores que trabalham em empresas consideradas socialmente responsáveis (Gil, 
2002; Carvalho-Freitas, 2009; CarvalhoFreitas \& Marques, 2010).

Também foi verificado que existe correlação entre os construtos do ICD-ST e do IVO, o que indica que a percepção de prestígio da empresa entre as demais organizações está relacionada à percepção de que a empresa não trata as PcDs como um desvio da normalidade. Sendo assim, pode-se dizer que as PcDs têm uma percepção positiva do prestígio da empresa que se relaciona à forma de ver, por parte da Serasa, a PCD, que não a coloca como um desviante de um padrão normal, mas que acredita que ela tenha capacidades e trabalha para potencializá-las. Nesse sentido, percebe a inclusão das PcDs como uma contribuição importante para o respeito da sociedade para a empresa, o que também foi identificado em pesquisas anteriores realizadas com gestores (Gil, 2002; Carvalho-Freitas, 2009; CarvalhoFreitas \& Marques, 2010).

Constata-se que a Serasa é uma organização em que a inclusão é um valor definido em suas políticas e perseguido em suas estratégias, sendo a concepção predominante de deficiência a inclusiva. Contemplando os diversos aspectos considerados relevantes no processo de inclusão identificados nas entrevistas, verificase que a inserção de $\mathrm{PcDs}$ não é uma tarefa simples, mas uma ação que contempla interesses e responsabilidades distintas e, às vezes, contraditórias, com vistas a construir uma nova forma de organização do trabalho em que seja possível às PcDs expressarem as suas necessidades e serem reconhecidas pelo seu desempenho no seio de uma estrutura em que a conformidade também é um valor.

\section{Conclusão}

A presente pesquisa possibilitou verificar que existe relação entre a forma como as PcDs veem suas possibilidades de trabalho e os valores organizacionais, associando a imagem positiva da organização às suas práticas de inserção de PcDs, que têm por foco a capacitação dessas pessoas, sua inserção em atividades compatíveis com suas potencialidades e a adequação das condições e práticas de trabalho, garantindo a acessibilidade. A premissa de garantir efetivamente o direito e cobrar resultados, sem privilégios para as $\mathrm{PcDs}$, tem um impacto positivo na forma como essas pessoas se veem, o que pode ser identificado pelas concepções de deficiência que compartilham.

Os resultados da investigação reafirmam a importância de se tratar a inserção de PcDs como um valor compartilhado pela organização, que se reflete em suas estratégias e políticas e na concretização das ações organizacionais de adequação das práticas de recursos humanos e do espaço físico, conforme indicado em pesquisa anterior (Schur et al., 2005). Além disso, os achados da pesquisa que indicam a boa percepção das possibilidades de trabalho pelas próprias PcDs e a associação da sua inclusão como fator relevante para o prestígio, admiração e respeito da sociedade para com a empresa abrem uma nova agenda de estudo: a reconfiguração identitária das PcDs. Será que, em circunstâncias de possibilidades reais de trabalho e de valorização social da organização em função da pertença das PcDs, poder-seia manter a premissa proposta por Goffman (2008) de uma identidade deteriorada?

No entanto, é importante salientar alguns limites deste estudo, como o número pequeno de respondentes na coleta de dados da etapa quantitativa. Além disso, os respondentes das entrevistas, segunda etapa da pesquisa, foram escolhidos pela empresa, o que limitou, assim, o acesso a outras pessoas, embora tenha sido nessa segunda etapa da pesquisa que apareceram as tensões existentes entre as responsabilidades da organização e das PcDs no processo de inclusão e em que foram anunciadas dificuldades de adaptação inicial pelas PCDs e pelos gestores. De qualquer forma, a aproximação realizada nesta pesquisa, que visou a conhecer a percepção das PcDs em uma organização-referência em inclusão, abre novas possibilidades de pesquisa sobre o processo de socialização das PcDs nas organizações.

Por último, é necessário sublinhar que estudos sobre realidades organizacionais que diferem do padrão convencional de inclusão de PcDs, além de oferecerem novas referências de atuação para os profissionais da área, podem contribuir para impulsionar reflexões e pesquisas sobre as tensões produzidas no mundo do trabalho, quando, por força de pressões sociais, internacionais e legais, as instituições e as empresas precisam se deparar com novas formas de organização do trabalho. 


\section{Maria Regina do Carmo Ávila-Vitor}

Mestre em Psicologia pela Universidade Federal de São João Del Rei, São João Del Rei - MG - Brasil.

E-mail: reginapsicologia@yahoo.com.br

\section{Maria Nivalda de Carvalho-Freitas}

Doutora em Administração pela Universidade Federal de Minas Gerais e professora adjunta do Departamento e Mestrado de Psicologia da Universidade Federal de São João Del Rei, São João Del Rei - MG - Brasil.

\section{Endereço para envio de correspondência:}

Avenida Nossa Senhora do Pilar, 93, Centro. CEP: 36.307-372. São João del Rei, MG.

Recebido 20/10/2011, 1a Reformulação 06/03/2012, Aprovado 13/04/2012.

\section{Referências}

Alencar, E. M. L. S. (1993). Um retrato da educação especial no Brasil. Em Aberto, 13(60), 5-10.

Amaral, L. A. (1996). Deficiência: questões conceituais e alguns de seus desdobramentos. Cadernos de Psicologia, 1, 3-12.

Araújo, J. N. G. (2007). Pessoas com deficiência: entre exclusão, integração e inclusão no mundo do trabalho. In Anais do XIV Encontro Nacional da Associação Brasileira de Psicologia Social, Rio de Janeiro.

Associação Brasileira de Normas e Técnicas. (2004). NBR 9050: acessibilidade a edificações, mobiliário, espaços e equipamentos urbanos. Recuperado em 4 fev., 2010, de http://www.mpdft.gov.br/sicorde/NBR9050-31052004.pdf

Batista, C. A. M. (2004). Inclusão: construção na diversidade. Belo Horizonte: Armazém de Idéias.

Brite, R. B. (2009). Análise das concepções de gestores sobre deficiência em pessoas que ocupam postos de trabalho em uma rede de supermercados. Dissertação de mestrado, Universidade do Estado do Rio de Janeiro, Rio de Janeiro.

Cardoso-Buckley, M. C. F. (2011). Valores influenciando a visão do ser humano e pesquisa em educação especial: uma reflexão. Revista Brasileira de Educação Especial, 17(Esp.), 17-22.

Carvalho-Freitas, M. N. (2009). Inserção e gestão do trabalho de pessoas com deficiência: um estudo de caso. RAC - Revista de Administração Contemporânea, 13(Esp.), 121-138.

Carvalho-Freitas, M. N., \& Gomes, R. P. (2010). Fatores estressores e formas de ver as possibilidades de trabalho de pessoas com deficiência. In Anais do VI Seminário Sociedade Inclusiva. Belo Horizonte, MG.

Carvalho-Freitas, M. N., \& Marques, A. L. (2007). A diversidade através da história: a inserção no trabalho de pessoas com deficiência. Organizações e Sociedade (UFBA), 14(41), 59-78.
Carvalho-Freitas, M. N., \& Marques, A. L. (2009). Pessoas com deficiência e trabalho: percepção de gerentes e pósgraduandos em administração. Psicologia: Ciência e Profissão, 29(2), 244-257.

Carvalho-Freitas, M. N., \& Marques, A. L. (2010). Inserção de pessoas com deficiência em organizações brasileiras: um estudo com empresas socialmente responsáveis. Revista Eletrônica de Gestão Organizacional, 8(3), 483-502. Recuperado em 20 de dez., 2011 de http://www.ufpe.br/ gestaoorg/index.php/gestao/article/viewFile/251/192

Deal, T., \& Kennedy, A. (1988). Corporate cultures: The rites and rituals of corporate life. London: Penguin.

Dias, D. V. (2005). Valores organizacionais, modelos e práticas de gestão de pessoas e comprometimento organizacional: um estudo em empresas selecionadas do setor siderúrgico mineiro. Tese de doutorado, Faculdade de Ciências Econômicas da Universidade Federal de Minas Gerais, Belo Horizonte, MG.

Enumo, S. R. (1998). Uma análise da evolução do conceito de deficiência mental. In L. Souza, M. M. P. Rodrigues \& M. F. Q. Freitas (Orgs.). Psicologia: Reflexões (im)pertinentes (pp. 347-371). São Paulo: Casa do Psicólogo.

Gil, M. (Coord.). (2002). O que as empresas podem fazer pela inclusão das pessoas com deficiência. São Paulo: Instituto Ethos.

Glat, R. (1995). A integração social dos portadores de deficiências: uma reflexão. Questões atuais em educação especial (Vol. I). Rio de Janeiro: Sette Letras.

Goffman, E. (2008). Estigma: notas sobre a manipulação da identidade deteriorada (4a. ed.). Rio de Janeiro: LTC.

Goyo, A. C., Manzini, E., Carvalho, M. B., Balthazar, M. F., \& Miranda, T. G. (1989). Justificativas para a formação profissional do deficiente mental: revisão da literatura brasileira especializada. Cadernos de Pesquisa, 69, 53-67. 
Instituto Brasileiro de Geografia e Estatística. (2010). Censo 2010. Recuperado em 20 dez., 2011, de http://www.ibge.gov.br/ home/estatistica/populacao/censo2010/T

Katz, D., \& Kahn, R. L. (1978). Psicologia social das organizações. São Paulo: Atlas.

Lara, G. B., Ávila, M. R. C., \& Carvalho-Freitas, M. N. (2008, jan./jun.). A questão cognitiva e afetiva na inserção das pessoas com deficiência no mercado de trabalho. Psicologia em Pesquisa, 2(1), 46-59.

Lei n. 8.213, de 24 de julho de 1991. (1991, 24 de julho). Dispõe sobre os planos de benefícios da previdência social e dá outras providências. Brasília. Recuperado em 26 jan., 2010 dehttp://www.planalto.gov.br/ccivil_03/Leis/L8213cons.htm

Lucca, E. A. (2008). Gestão para um mundo melhor: o empresário que criou um inovador modelo de gestão que concilia o sucesso das pessoas, da empresa e do país. Rio de Janeiro: Elsevier.

Malhotra, N. (2001). Pesquisa de marketing: uma orientação aplicada (3a. ed.). Porto Alegre: Bookman.

Mendes, E. G. (1995). Deficiência mental: a construção científica de um conceito e a realidade educacional. Tese de doutorado, Instituto de Psicologia, Universidade de São Paulo, São Paulo.

Mendes, E. G., Ferreira, J. R., \& Nunes, L. R. O. P. (2003). Integração/inclusão: o que revelam as teses e dissertações em educação e psicologia. In F. P. Nunes Sobrinho (Org.). Inclusão educacional: pesquisas e interfaces (pp. 98-149). Rio de Janeiro: Livre Expressão.

Ministério do Trabalho e Emprego. (2010). Características do emprego formal segundo a relação anual de informações sociais - 2010. Recuperado em 20 out., 2011, de http://www. mte.gov.br/rais/2010/arquivos/Resultados_Definitivos.pdf

Monteiro, A. P. H. (2006). Há mudanças nas concepções do professor do ensino fundamental em relação à inclusão após a inserção de alunos deficientes? Dissertação de mestrado em educação, Faculdade de Filosofia e Ciências, Universidade do Estado de São Paulo, Marília, SP.

Moraes, M. O, Lima, L. F. F., \& Mansolo, C. C. (2011). Variações sobre ver e não ver: dois relatos de casos. Arquivos Brasileiros de Psicologia, 63(1), 1-110

Nascimento, L. C., Damasceno, G. J. B., \& Assis, L. J. (2011). Mercado de trabalho para as pessoas com deficiência em Betim/MG. Pesquisas e Práticas Psicossociais, 6(1), 92-101.

Nepomuceno, M. F., \& Carvalho-Freitas, M. N. (2008). As crenças e percepções dos gerentes e as possibilidades de trabalho das pessoas com deficiência. Psicologia em Pesquisa, 2(1), 81-94.

Oliveira, C., \& Tamayo, A. (2004). Inventário de perfis de valores organizacionais. Revista de Administração (USP), 39(2), 129-140.

Omote, S. (1987). Estereótipos a respeito de pessoas deficientes. Didática, 23(1), 167-180.

Omote, S. (1990). Aparência e competência em educação especial. Temas em Educação Especial, 1(1), 11-26.

Omote, S. (1997). Atratividade física facial e prognóstico. Psicologia, Teoria e Pesquisa, 13(1), 113-117.

Omote, S. (1999). Normalização, integração, inclusão. Ponto de Vista, 1(1), 4-13.

Pessotti, I. (1984). Deficiência mental: da superstição à ciência. São Paulo: T. A. Queiroz. (Biblioteca de Psicologia e Psicanálise, v. 4)

Piccolo, G. M., Moscardini, S. F., \& Costa, V. B. (2010). A historiografia das produções em periódicos de Sadao Omote. Revista Brasileira de Educação Especial, 16(1), 107-126.

Serasa Experian. (2011). Recuperado em 20 out., 2011, de http:// www.serasaexperian.com.br/serasaexperian/institucional/ missao/visao.htm

Ribas, J. B. C. (2008). Por que empregar pessoas com deficiência? In M. N. Carvalho-Freitas \& A. L. Marques (Orgs.). Trabalho e pessoas com deficiência: pesquisas, práticas e instrumentos de diagnóstico (pp. 211-217) Curitiba: Juruá.

Ribeiro, M. A., \& Carneiro, R. (2009). A inclusão indesejada: as empresas brasileiras face à Lei de Cotas para pessoas com deficiência no mercado de trabalho. O\&S Organização e Sociedade (UFBA), 16(50), 545-564.

Sassaki, R. K. (1999). Inclusão: construindo uma sociedade para todos. Rio de Janeiro: WVA.

Schein, E. H. (1992). Organizational culture and leadership (2a. ed.). San Francisco: Jossey-Bass.

Schein, E. H. (1999). The corporate culture survival guide. San Francisco: Jossey-Bass.

Schur, L., Kruse, D., \& Blanck, P. (2005). Corporate culture and the employment of persons with disabilities. Behavioral Sciences and the Law, 23, 3-20.

Shannon, C. D., Tansey, T. N., \& Schoen, B. (2009, Oct./ Dec.). The effect of contact, context, and social power on undergraduate attitudes toward persons with disabilities. Journal of Rehabilitation, 75(4), 11-18.

Silva, O. M. (1993). Uma questão de competência. São Paulo: Memnon.

Tamayo, A. (2008). Valores organizacionais. In M. M. M. Siqueira et al. Medidas do comportamento organizacional: ferramentas de diagnóstico e de gestão (pp. 309-340). Porto Alegre: Artmed.

Tamayo, A., \& Gondim, M. G. C. (1996, abr.jun.). Escala de Valores Organizacionais. Revista de Administração, 31(2), 62-72.

Tanaka, E. D. O., \& Manzini, J. E. (2005). O que os empregadores pensam sobre o trabalho da pessoa com deficiência? Revista Brasileira de Educação Especial, 11(2), 273-294. 